\title{
Molecular Genetic study to detect Numerical Aberration of Cyclin D1 (CCND1) Gene by using Fluorescence in Situ Hybridization technique as a diagnostic and prognostic tool in Oral Squamous Cell Carcinoma
}

\author{
Authors \\ Savita Yadav ${ }^{1}$, Dr Dhiraj Saxena ${ }^{2 *}$, Dr Jaskaran Singh ${ }^{3}$, Brijesh Kumar ${ }^{4}$ \\ ${ }^{1}$ Senior Demonstrator, Anatomy Department. S.M.S. Medical College, Jaipur (Raj.) \\ ${ }^{2}$ Senior Professor, Anatomy Department, S.M.S. Medical College, Jaipur (Raj.) \\ ${ }^{3}$ Assistant Professor, Anatomy Department, S.P. Medical College, Jaipur (Raj.) \\ ${ }^{4}$ Scientist, AGILE (Advanced Genomics Institute And Laboratory Medicine) Delhi (India) \\ *Corresponding Author \\ Dr Dhiraj Saxena \\ Senior Professor, Anatomy Department, S.M.S. Medical College, Jaipur, Rajasthan, India
}

\begin{abstract}
Molecular changes in OSCC are well documented with occurrence of a wide range of genetic damage. Cyclin D1 gene located on chromosome 11 13 is a positive regulator of the cell cycle. It encodes a nuclear protein that plays an important role in the tumorigenesis.

Materials and Methods: Paraffin embedded tumor sections were collected from histological confirmed OSCC patients from the Out Patient Department (OPD) of Oncology and ENT and department of pathology of the institution respectively. Buccal smear samples were obtained from 30 healthy controls. FISH technique was used to detect the numerical aberrations of Cyclin D1 using the Vysis protocol.

Results: Cyclin D1 gene numerical aberrations were not found in controls. $18(22.5 .0 \%)$ cases were positive for Cyclin D1 gene numerical aberrations in OSCCs. Low level amplification were in 9 (11.3\%), high level or cluster amplification were in $6(7.5 \%)$, polysomy were in $2(2.5 \%)$, deletion of CCND1 gene was in 1 (1.3\%). P-value was greater than $>0.05$ so there was not statistically significant association of gender, histopathological differentiation and site of carcinoma, risk factors with numerical aberrations of Cyclin D1 gene. Numerical aberrations of Cyclin D1 gene showed a significant association with lymph node metastasis $(P=0.038)$ and stage of Carcinoma $(P=0.009)$.

Conclusion: Analysis of the CCND1 numerical aberrations using FISH on paraffin embedded tumor section may be a useful and practical method for predicting aggressive tumors, recurrence and clinical outcome in patients with OSCCs.

Keywords: Oral Squamous Cell Carcinoma, Fluorescence in Situ Hybridization, Aberrations, Cyclin D1.
\end{abstract}

\section{Introduction}

Cancer is a major public health problem in the world. Head and neck squamous cell carcinomas (HNSCCs) is the most prevalent malignant neoplasm (90\% approximately) $)^{1,2}$.
Cancer is the second leading cause of death globally, and is responsible for an estimated 9.6 million deaths in 2018. Globally, about 1 in 6 deaths is due to cancer. Around one third of deaths from cancer are due to the 5 leading behavioral and dietary risks: high body mass 
index, low fruit and vegetable intake, lack of physical activity, tobacco use, and alcohol use. Tobacco use is the most important risk factor for cancer and is responsible for approximately $22 \%$ of cancer deaths ${ }^{3}$.

Oral cancers have a multifaceted etiology. Lifestyle and environmental factors has been identified as the risk factor for oral cancers. Smoking, tobacco chewing, and alcohol consumption are widely considered to be major preventable risk factors ${ }^{4}$.

OSCC arises through a multistep process of genetic alterations usually as a result of individual predisposition and the exposure to environmental agents, thus cancer is a genetic disease of somatic cells ${ }^{5}$. The aggressiveness of a malignancy due to chromosomal and genetic alterations can affect tumor progression, treatment and prognosis ${ }^{6}$. The genetic changes occurring in OSCC have retained the focus attention in dentistry, mainly in oral and maxillofacial pathology ${ }^{7}$

OSCC most commonly affects the ventral surface of tongue and floor of mouth because they are lined by thin non-keratinized stratified squamous epithelium. Carcinogens like tobacco products and alcohol in solution constantly accumulate in the floor of mouth and bathe the tissues of the floor of mouth and ventrum of tongue. So these carcinogens rapidly penetrate the epithelium to reach the progenitor cell ${ }^{8}$.

Recently molecular cytogenetic has expanded their role in medical field rapidity and plays a major role in cancer disease diagnosis and management. Among the advanced molecular techniques, fluorescence in-situ hybridization (FISH) has a perfect balance of high specificity and sensitivity with advantage of rapidity, which is being used in routine clinical laboratory for genomic diagnosis 9 .

Fluorescent in situ hybridization (FISH) is widely used for the localization of genes and specific genomic regions on target chromosomes. FISH uses fluorescent probes that bind to only those parts of chromosome with which they show a high degree of sequence complimentarity. The interphase FISH technique produces direct visualization of chromosomal aberrations in cell nuclei using fluorescently-labeled DNA probes ${ }^{10}$.

Deregulation of the cell cycle mechanism is a critical event in carcinogenesis and it is emerging as a central theme in oral carcinogenesis. The genes involved in cell cycle regulation represent targets of oncogenic abnormalities among which Cyclin D1 is most involved ${ }^{11}$.

In human cells, cell division is controlled by the activity of Cyclin-dependent kinases (CDKs) and their essential activating coenzymes, the CDK inhibitors, which may be influenced by genetic variations in the corresponding genes ${ }^{12}$.

Cyclin D1 proto-oncogene is an important regulator of G1 to S-phase transition in numerous cell types from diverse tissue. CCND1 is a protooncogene is located on the long arm of chromosome 11 (band 11q13). A frequent target in carcinogenesis is the deregulation of $\mathrm{G} 1$ to $\mathrm{S}$ phase progression of the cell cycle. The transition through $\mathrm{G} 1$ to $\mathrm{S}$ phase is regulated by cyclins, cyclin-dependent kinases (CDK)-CDK4 and CDK6 and their inhibitors. Cyclin D1 is a key regulatory protein at G1/S checkpoint of the cell cycle. It forms complexes with CDK4 or CDK6 and is responsible for the phosphorylation of the retinoblastoma tumour suppressor protein, resulting in the release of E2F transcription factors that allow cell to enter into $S$ phase. The G1/S checkpoint is frequently altered in many epithelial tumours and may confer growth advantage and enhanced tumor genesis ${ }^{13}$.

Cyclin D1 have been detected in oral squamous cell carcinomas (OSCCs), suggesting that abnormalities of these genes may play an important role in the genesis or progression of OSCCs and serve as independent prognostic indicators. The detection of CCND1 using a simple and sensitive method would be valuable for the development of effective treatment modalities for oral cancer ${ }^{14}$.

Alarming numbers of the population from North India including state of Rajasthan and adjoining region currently suffering from cancer and a 
substantial numbers of patients comprise of OSCCs. Understanding the epidemiology and the risk factors for oral cancers can help early identification and prompt treatment of patients with oral cancers.

The present study aim was to detect Cyclin D1 gene numerical aberrations in OSCCs by using fluorescence in situ hybridization technique (FISH).

\section{Materials and Methods}

\section{Tissues and Patient Characteristics}

Formalin-fixed paraffin embedded tumor section obtained from 50 OSCC patients (42 males, 8 females). Paraffin embedded tumor section were collected from the Out Patient Department (OPD) of Oncology and ENT and department of pathology of institution respectively. FISH was carried on buccal smear samples and thin sections $(4 \mu)$ cut from formalin-fixed, paraffin-embedded tissue blocks according vysis protocol.

The institutional ethics committee cleared the protocol and the information pertaining to the patients. Informed consent was obtained from all patients in accordance with our Institutional ethics committee guidelines. Clinical data of all patients with regard to of patients including age, gender, weight, height, blood pressure, dietary habits, tobacco chewing, smoking, alcohol consumption, duration of symptoms and the presence of lymph node metastasis factors helpful in study were record.

The mean age of controls and patients were $45.27 \pm 10.03$ years and $46.80 \pm 12.34$ years (range, 22-70 yeras). The mean of controls and patients were $22.67 \pm 3.15 \mathrm{~kg} / \mathrm{m}^{2}$ and $6721.56 \pm 3.2 \mathrm{~kg} / \mathrm{m}^{2}$. The 50 OSCC samples were derived from the buccal mucosa (23), soft palate (3), lateral surface of tongue (11), retro-mandibular region (3), root of tongue (4), lower alveolar mucosa (6) and the floor of the mouth (4). The clinical staging was defined on the basis of the American Joint Committee on Cancer (AJCC) ${ }^{14}$ TNM classification: Stage I (12), stage II (12), stage III (8),stage IV (7), Stage IV (2) and stage IVC (9).
The tumors were classified histopathologically in to well (17), moderately (26) and poorly differentiated (7) according to their cellular differentiation as defined in the World Health Organization classification ${ }^{15}$. Duration of diagnosis after first sign and symptoms of OSCC was 5.8 \pm .7 months (range, 1-24 months).

\section{Fluorescence Microscopy}

A Leica DM2500 Fluorescence microscope equipped with 10x, 20x, 40x dry, and 100x oil immersion objectives with triple-pass filter for spectrum Green/Spectrum Orange and DAPI (Vysis) was used to count the fluorescent signals. To capture images the fluorescent microscope is attached to a digital camera Leica DCF420C installed on the C-mount of the DM2500 and results were interpreted using Leica application suite (LAS) software for image acquition (fixed images). Overlapping and damaged nuclei were ignored and only intact nuclei were evaluated. Hybridization signals were counted in 200 interphase nuclei.

\section{Evaluation of FISH analysis}

Evaluation of the preparation was observed by counting 200 interphase nuclei. Enumeration of the fluorescent signals was done in 200 nuclei per slide under objective 100x, using a Leica DM2500 fluorescent microscope equipped with single band sets for DAPI, Fluorescein isothiocyanate (FITC) green and Tetramethyl rhodamine spectrum orange to discriminate the color signals of green for chromosome 11 centromeric DNA and orange for Cyclin D1 during scoring.

Dual Probe Color setup:-

Green Signal: for chromosome 11 centromeric DNA

Orange Signal: for Cyclin D1 gene on chromosome 11

The hybridized signals appear as small spot since the region of a chromosome occupies only a small region of the nucleus. At least 200 nuclei were scored using a 100X objective in each defined area, and each nucleus was assessed for the chromosome copy number. In a cell with normal copy number of the Cyclin D1 gene (11q13 
region) and chromosome 11 (11p11.11-q11), two respective spectrum orange color signal for Cyclin D1 (CCND1) and two respective green color signal (chromosome11 (11p11.11q11)) were observed.

\section{Types of chromosomal aberrations}

1. Normal (No aberrations)- In a nucleus, two respective spectrum orange color signal for Cyclin D1(CCND1) gene (11q13 region) and two respective green color signal for chromosome11 (11p11.11q11 region). The signals ratio of the orange signals to the green signals is 1. [Figure No.1 Buccal cells, Figure No.2(A) Tumor cells]

2. Low Level amplification- Abnormal copy number of Cyclin D1(CCND1) gene was indicated by 3 or more respective orange color signals with two respective green color signal (chromosome11 (11p11.11q11)). If the signals ratio of the orange signals to the green signals is more than 2, it was considered positive amplification. When $\geq 20 \%$ of the nuclei exhibited $\geq 3$ signals for CCND1, the tumor was considered to have a low Level amplification. [Figure No.2(B)]

3. High (Cluster type) level amplificationClusters of CCND1 (orange) signals were present in nucleus with two respective green color signal (chromosome11 (11p11.11q11)). When clusters of CCND1 signals (orange) were observed in more than $20 \%$ of 200 nuclei, this was considered as showing "Cluster-type amplification of CCND1. [Figure No.2(C)]

4. Polysomy- The copy number of chromosome 11 (11p11.11q11) were quantified by enumeration of the respective centromeric probe (11p11.11-q11) green signal within the cell. In a nucleus, green signals were $>2$ and orange signals were also quantified according green signals. [Figure No.2(D)]

5. Deletion of CCND1 gene (Missing) - In one nucleus, there were one or no orange color signal for Cyclin D1 (CCND1) and two respective green color signal for chromosome11

(11p11.11q11).

No.2(E)]

\section{Statistical Analysis}

The results of FISH were compared with the clinic pathologic information of patients included patient age, gender, tumor site, disease stage, histopathology differentiation and the presence of lymph node metastasis, using Microsoft statistical package of social science (SPSS) computer program, version 19.0 for windows. Mean and SD were derived for the continue parameters. Pearson Chi-square and the 2-tailed Fisher's exact test (FET) were used for comparison of parameters association among themselves. The significant $\mathrm{p}$ value in these tests is $<0.05$.

\section{Results}

Table 1 represented the distribution of study population according to numerical aberrations of Cyclin D1 gene. Numerical aberrations was found positive in $18(22.5 \%)$ of 50 patients with primary OSCCs. Controls were negative for numerical aberrations of Cyclin D1 gene.

Table 2 shows the distribution of study population according to types of numerical aberration of Cyclin D1 gene. Out of 50 OSCC patients, low level amplification were in $9(11.3 \%)$, high level or cluster amplification were in $6(7.5 \%)$, polysomy were in 2(2.5\%), deletion of Cyclin D1 (CCND1 gene) was in $1(1.3)$ and $32(40 \%)$ have no aberration.

Table 3 showed that $\mathrm{p}$-value was greater than $>0.05$, so there was not significant association of gender, primary site of carcinoma, histopathological differentiation of OSCC with numerical aberrations of Cyclin D1 gene. P-value (0.004 and 0.038) was less than $<0.05$, so a significant association was present between stage of OSCC and lymph node metastasis with numerical aberrations of Cyclin D1 gene.

Table No 4 showed the association of risk factors (alcohol consumption, tobacco chewing smoking and socio-economic status) with numerical aberrations of CCND1 gene was not significant. 
Table No.1 Distribution of study population according to Numerical aberrations of Cyclin D1 gene

\begin{tabular}{|l|c|c|c|c|c|c|c|}
\hline \multirow{2}{*}{} & \multicolumn{2}{|c|}{ Numerical aberrations of Cyclin D1gene } & \multicolumn{2}{|c|}{} \\
\cline { 3 - 8 } \multicolumn{2}{|c|}{} & \multicolumn{2}{|c|}{ Negative } & \multicolumn{2}{|c|}{ Positive } & \multicolumn{2}{c|}{ Total } \\
\cline { 3 - 8 } & $\mathrm{n}$ & $\%$ & $\mathrm{n}$ & $\%$ & $\mathrm{n}$ & $\%$ \\
\hline $\begin{array}{l}\text { Study } \\
\text { Groups }\end{array}$ & OSCC Patient & $\mathbf{3 2}$ & $\mathbf{4 0 . 0}$ & $\mathbf{1 8}$ & $\mathbf{2 2 . 5}$ & $\mathbf{5 0}$ & $\mathbf{6 2 . 5}$ \\
\cline { 2 - 8 } & Control & $\mathbf{3 0}$ & $\mathbf{3 7 . 5}$ & $\mathbf{0}$ & $\mathbf{0 . 0}$ & $\mathbf{3 0}$ & $\mathbf{3 7 . 5}$ \\
\hline Total & & $\mathbf{6 2}$ & $\mathbf{7 7 . 5}$ & $\mathbf{1 8}$ & $\mathbf{2 2 . 5}$ & $\mathbf{8 0}$ & $\mathbf{1 0 0 . 0}$ \\
\hline
\end{tabular}

Table No. 2 Distribution of study population according to Types of Numerical aberration of Cyclin D1 gene

\begin{tabular}{|c|c|c|c|c|c|c|c|c|c|c|c|c|c|}
\hline & \multicolumn{10}{|c|}{ Types of Numerical aberration of Cyclin D1 gene in Tissue } & \multirow{2}{*}{\multicolumn{2}{|c|}{ Total }} \\
\hline & & \multicolumn{2}{|c|}{$\begin{array}{c}\text { Low level } \\
\text { amplification }\end{array}$} & \multicolumn{2}{|c|}{$\begin{array}{c}\text { High level or Cluster } \\
\text { amplification }\end{array}$} & \multicolumn{2}{|c|}{ Polysomy } & \multicolumn{2}{|c|}{ Deletion } & \multicolumn{2}{|c|}{ No aberration } & & \\
\hline & & $\mathrm{n}$ & $\%$ & $\mathrm{n}$ & $\%$ & $\mathrm{n}$ & $\%$ & $\mathrm{n}$ & $\%$ & $\mathrm{n}$ & $\%$ & $\mathrm{n}$ & $\%$ \\
\hline \multirow[t]{2}{*}{$\begin{array}{l}\text { Study } \\
\text { Groups }\end{array}$} & $\begin{array}{l}\text { OSCC } \\
\text { Patient } \\
\end{array}$ & 9 & 11.3 & 6 & 7.5 & 2 & 2.5 & 1 & 1.3 & 32 & 40.0 & 50 & 62.5 \\
\hline & Control & $\mathbf{0}$ & 0.0 & $\mathbf{0}$ & $\mathbf{0 . 0}$ & $\mathbf{0}$ & $\mathbf{0 . 0}$ & $\mathbf{0}$ & $\mathbf{0 . 0}$ & 30 & 37.5 & 30 & 37.5 \\
\hline \multicolumn{2}{|l|}{ Total } & 9 & 11.3 & 6 & 7.5 & 2 & 2.5 & 1 & 1.3 & 62 & 77.5 & 80 & 100.0 \\
\hline
\end{tabular}

*Monosomy has zero value

Table No. 3 Association between Numerical aberrations of Cyclin D1 gene and various parameters

\begin{tabular}{|c|c|c|c|c|c|c|c|c|}
\hline \multirow{3}{*}{ Various parameters } & & \multicolumn{4}{|c|}{$\begin{array}{c}\text { Numerical aberrations of Cyclin } \\
\text { D1 gene }\end{array}$} & & & \multirow{3}{*}{ P-value } \\
\hline & & \multicolumn{2}{|c|}{ Negative } & \multicolumn{2}{|c|}{ Positive } & \multicolumn{2}{|c|}{ Total } & \\
\hline & & $\mathrm{n}$ & $\%$ & $\mathrm{n}$ & $\%$ & $\mathrm{n}$ & $\%$ & \\
\hline \multirow{2}{*}{ Gender } & Male & 26 & 52.0 & 16 & 32.0 & 42 & 84.0 & \multirow[t]{2}{*}{$0.694 *$} \\
\hline & Female & 6 & 12.0 & 2 & 4.0 & 8 & 16.0 & \\
\hline \multirow{6}{*}{$\begin{array}{l}\text { Primary Site of } \\
\text { Carcinoma }\end{array}$} & Buccal mucosa & 13 & 26.0 & 10 & 20.0 & 23 & 46.0 & \multirow[t]{6}{*}{ 0.118* } \\
\hline & Soft palate & $\mathbf{0}$ & $\mathbf{0 . 0}$ & 3 & 6.0 & 3 & 6.0 & \\
\hline & Lateral surface of tongue & 9 & 18.0 & 2 & 4.0 & 11 & 22.0 & \\
\hline & Lower alveolar mucosa & 4 & 8.0 & 2 & 4.0 & 6 & 12.0 & \\
\hline & Retro-mandibular region & 3 & 6.0 & $\mathbf{0}$ & $\mathbf{0 . 0}$ & 3 & 6.0 & \\
\hline & Root of tongue & 3 & 6.0 & 1 & 2.0 & 4 & 8.0 & \\
\hline \multirow{3}{*}{$\begin{array}{l}\text { Histopathological } \\
\text { grade of OSCC }\end{array}$} & Moderately differentiated & 15 & 30.0 & 11 & 22.0 & 26 & 52.0 & \multirow{3}{*}{$\begin{array}{l}0.140^{\#} \\
0.129 *\end{array}$} \\
\hline & Poorly differentiated & 3 & 6.0 & 4 & 8.0 & 7 & 14.0 & \\
\hline & Well differentiated & 14 & 28.0 & 3 & 6.0 & 17 & 34.0 & \\
\hline \multirow{2}{*}{\begin{tabular}{|l|l|} 
Lymph node \\
metastasis
\end{tabular}} & No & 24 & 48.0 & 8 & 16.0 & 32 & 64.0 & \multirow[t]{2}{*}{$\mathbf{0 . 0 3 8}^{\#}$} \\
\hline & Yes & 8 & 16.0 & 10 & 20.0 & 18 & 36.0 & \\
\hline \multirow[t]{6}{*}{ Stage of OSCC } & $\mathrm{I}$ & 11 & 22.0 & 1 & 2.0 & 12 & 24.0 & \multirow[t]{6}{*}{$0.009 *$} \\
\hline & II & 10 & 20.0 & 2 & 4.0 & 12 & 24.0 & \\
\hline & III & 5 & 10.0 & 3 & 6.0 & 8 & 16.0 & \\
\hline & IVA & 3 & 6.0 & 4 & 8.0 & 7 & 14.0 & \\
\hline & IVB & $\mathbf{0}$ & $\mathbf{0 . 0}$ & 2 & 4.0 & 2 & 4.0 & \\
\hline & IVC & 3 & $\begin{array}{l}6.0 \\
\end{array}$ & 6 & 12.0 & 9 & 18.0 & \\
\hline
\end{tabular}

\#Pearson Chi-Sqaure, *Fisher's Exact test 
Table No 3 Association between Numerical aberrations of Cyclin D1 gene and various parameters

\begin{tabular}{|c|c|c|c|c|c|c|c|c|}
\hline \multirow{3}{*}{ Risk Factors } & & \multicolumn{4}{|c|}{$\begin{array}{l}\text { Numerical aberrations of Cyclin } \\
\text { D1 gene }\end{array}$} & & & \multirow{3}{*}{ P-value } \\
\hline & & \multicolumn{2}{|c|}{ Negative } & \multicolumn{2}{|c|}{ Positive } & \multicolumn{2}{|c|}{ Total } & \\
\hline & & $\mathrm{n}$ & $\%$ & $\mathrm{n}$ & $\%$ & $\mathrm{n}$ & $\%$ & \\
\hline \multirow{3}{*}{ Alcohol Consumption } & No & 20 & 40.0 & 9 & 18.0 & 29 & 58.0 & \multirow[t]{3}{*}{$0.751^{\#}$} \\
\hline & Occasionally & 3 & 6.0 & 2 & 4.0 & 5 & 10.0 & \\
\hline & Regular & 9 & 18.0 & 7 & 14.0 & 16 & 32.0 & \\
\hline \multirow[t]{4}{*}{ Smoking } & No & & 26.0 & 10 & 20.0 & 23 & 46.0 & \multirow[t]{4}{*}{$0.211 *$} \\
\hline & Mild & $\mathbf{0}$ & $\mathbf{0 . 0}$ & 3 & 6.0 & 3 & 6.0 & \\
\hline & Moderate & 9 & 18.0 & 2 & 4.0 & 11 & 22.0 & \\
\hline & Severe & 4 & 8.0 & 2 & 4.0 & 6 & 12.0 & \\
\hline \multirow[t]{4}{*}{ Tobacco Chewing } & No & 6 & 12.0 & 5 & 10.0 & 11 & 22.0 & \multirow[t]{4}{*}{$0.769 *$} \\
\hline & Mild & 2 & 4.0 & 1 & 2.0 & 3 & 6.0 & \\
\hline & Moderate & 3 & 6.0 & 3 & 6.0 & 6 & 12.0 & \\
\hline & Severe & 21 & 42.0 & 9 & 18.0 & 30 & 60.0 & \\
\hline \multirow{4}{*}{$\begin{array}{l}\text { Socio-economic } \\
\text { Status }\end{array}$} & Upper Class(I) & 12 & 24.0 & 6 & 12.0 & 18 & 36.0 & \multirow[t]{4}{*}{$0.670 *$} \\
\hline & Upper Middle Class(II) & 12 & 24.0 & 10 & 20.0 & 22 & 44.0 & \\
\hline & Middle Class(III) & 4 & 8.0 & 1 & 2.0 & 5 & $\mathbf{1 0 . 0}$ & \\
\hline & Lower Middle Class(IV) & 4 & 8.0 & 1 & 2.0 & 5 & $\mathbf{1 0 . 0}$ & \\
\hline
\end{tabular}

"Pearson Chi-Sqaure, *Fisher's Exact test

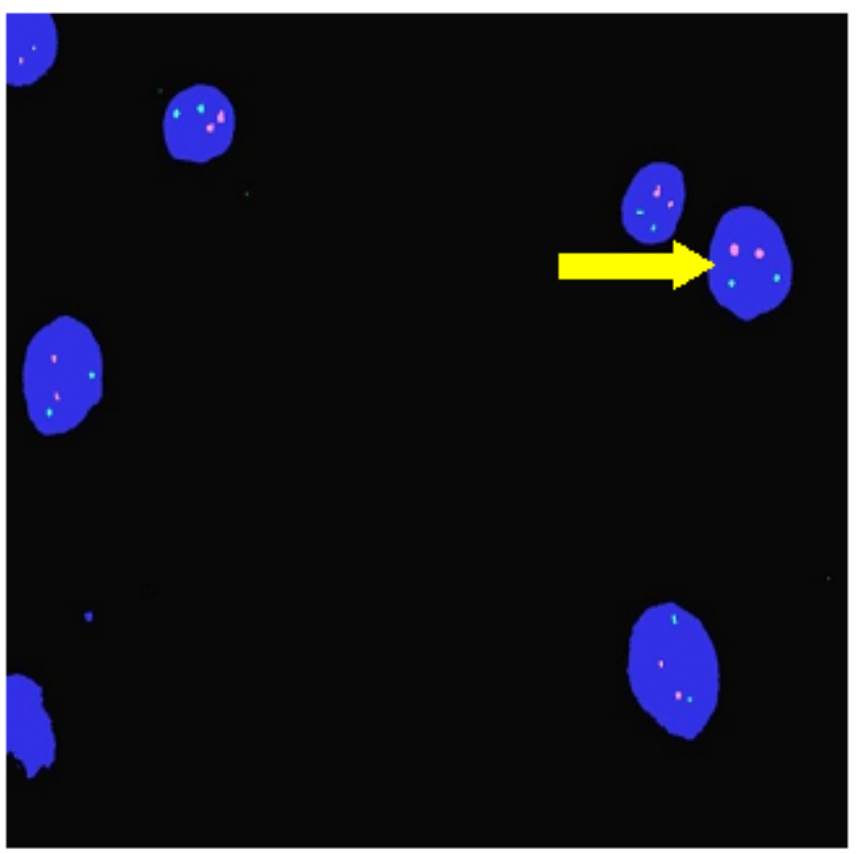

Figure No. 1 Representative result of fluorescence in situ hybridization (FISH) for Cyclin D1 gene. Normal Buccal cell interphase showing two green signals for chromosome 11 centromere and two orange signals for Cyclin D1 gene with 4,6-diamidino-2-phenylindole, dihydrochloride counterstaining. 


\section{JMSCR Vol||07||Issue||11||Page 595-604||November}
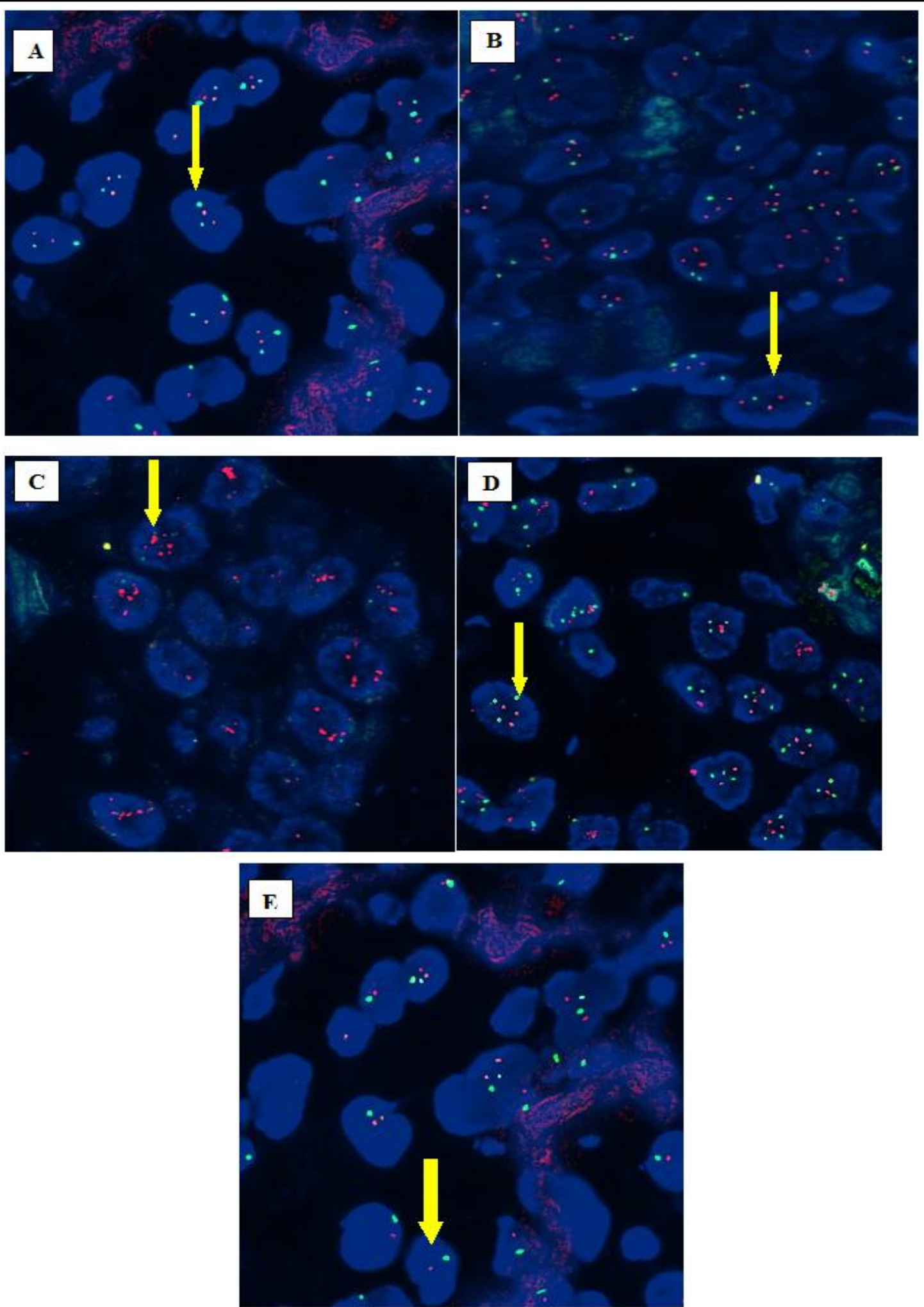

Figure 2 Representative results of fluorescence in situ hybridization (FISH) for Cyclin D1 (CCND1) gene in Formalin fixed paraffin section of Tumor (OSCC) in interphase nuclei. (A). Normal, normal cells were hybridized with probes for the chromosome 11 centromere (green) and the Cyclin D1 gene (orange), with 4,6-diamidino-2-phenylindole, dihydrochloride counterstaining. (B). Low level amplification, There were significantly more cells with more orange than green spots, (C) High level or cluster amplification, (D) Polysomy, FISH showed three copies of both signals. This case shows multiple copies of CCND1 with chromosome 11 polysomy, (E) Deletion, FISH showed one green and one orange signal. 


\section{Discussion}

In the present study, we explored the feasibility using Cyclin D1 as a prognostic marker in OSCC by the FISH method. HNSCC, the amplification of 11q13 may be an important biologic marker for poor prognosis ${ }^{17}$. Miyamoto $\mathrm{R}$ et al ${ }^{18}$ The CCND1 numerical aberration was identified in $42.0 \%$ (21 of 50 patients) of tumors. 21 tumors that showed the CCND1 numerical aberration, 5 (24\%) had multiple single copies of CCND1 associated with chromosome 11 polysomy. The presence of the CCND1 numerical aberration did not correlate significantly with age, gender, or tumor site. Tumors with a poorly differentiated and/or a more diffuse invasive pattern were associated significantly with the CCND1 numerical aberration.

Myo et $\mathrm{al}^{19}$ has concluded that the aberration in Cyclin D1 numbers to be valuable in identification of patients at high risk of late lymph node metastasis in stage I and II OSCCs. On the other hand Rodrigo et $\mathrm{al}^{20}$ in their study correlated CCND1 amplification with clinicopathological parameters. Amplification-positive cases were found at each anatomic site; CCND1amplification was more frequent in $\mathrm{T} 4$ tumours and was associated with increased regional lymph node metastasis. No relationship was observed between CCND1 amplification and histopathological differentiation which was in agreement with the present study.

Interestingly, Kaminagakura et $\mathrm{al}^{21}$ in their study found significant correlation between young age ( $<40$ years) and CCND1 amplification, but failed to find any influence on prognosis. Pathare et $\mathrm{al}^{22}$ found a significant correlation of $+11 \mathrm{q} 13$ with high-grade OSCC. Nimeus et $\mathrm{al}^{23}$ have reported positive Cyclin D1 amplification as low as $16 \%$ in SCC of oral cavity while $56.5 \%$ in SCC of tongue was reported by Fuji et $\mathrm{al}^{24}$. Huang $\mathrm{X}$ et $\mathrm{al}^{25}$ in their study where clinicopathologic features of the studied cases failed to show any significant correlation with 11q13 amplification. Monteiro L $\mathrm{S}$ et $\mathrm{al}^{26}$ found that $43.3 \%$ (26) of the cases showed the presence of numerical aberrations. In
19 cases $(31.7 \%)$, there were more than six signals or cluster formations present per nuclei. CCND1 gene status was not correlated with clinicopathological features. They could not find an association of numerical aberrations in the 11 13 region such as CCND1 amplification with any clinical and pathological variables such as nodal metastasis and also with survival. This could be due to the small size of our series, differences in tumour sites or possible differences in geographic populations.

Uazawa $\mathrm{N}$ et $\mathrm{al}^{14}$ found that CCND1 numerical aberration was identified in 28 of 57 primary oral SCCs (49.1\%). Only 9 tumors had multiple single copies of CCND1 associated with chromosome 11 polysomy. Of the 28 tumors that exhibited CCND1 numerical aberrations, 8 tumors demonstrated cluster-type amplification of CCND1. CCND1 numerical aberration was associated significantly with reduced disease-free survival $(\mathrm{P}=0.0004)$ and overall survival $(\mathrm{P}$ $=0.0179)$.

Mahdey $\mathrm{H} \quad \mathrm{M}$ et $\mathrm{al}^{27}$ observed positive amplification of Cyclin D1 was in $72 \%$ (36) of OSCCs. Detection of positive amplification for Cyclin D1 was observed in $88 \%$ (22) and $56 \%$ (14) of the tongue and cheek tumors, respectively, where the difference was statistically significant $(\mathrm{P}=0.012)$. Lymph node metastasis of cheek SCCs showed a trend towards a significant association $(\mathrm{P}=0.098)$ with cyclin $\mathrm{D} 1$ amplification whereas the lymph node metastasis of tongue SCC was clearly not significant $(\mathrm{P}=0.593)$. There was a statistically significant correlation between Cyclin $\mathrm{D} 1$ positivity and survival rate $(\mathrm{P}=0.009)$ for overall SCC cases and $(\mathrm{P}<0.001)$ for cheek SCC cases.

Ramadan O R et al ${ }^{10}$ detected that $8(26.7 \%)$ of the 30 formalin-fixed paraffin blocks cases were scored positive for CCND1 amplification and the relation between FISH and the demographic data of the patients like the age, the sex, the site of the tumor, the lymph node involvement, the clinical stage, and the histological grade were not statistically significant. $(\mathrm{P}=0.47,0.67,0.33,0.15$, 
0.58 and 0.67 respectively). Many studies have been done on Cyclin D1 in OSCC, and even though the controversy exists in the scientific literature, it opens a window of opportunity for further discussion and research in different tumours with additional different criteria like lymph node involvement and metastasis.

\section{Conclusion}

1) Evaluating the CCND1 numerical aberration by FISH on paraffin embedded specimens before treatment also helps in the selection of more appropriate treatment for patients with OSCCs. Therefore, we conclude that the CCND1 numerical aberration is a useful tool, not only as a prognostic factor independently of the TNM classification, but also as an indicator to determine the most appropriate treatment for patients with OSCCs.

2) To improve the overall survival rate of OSCC patients, more intensive treatment should be given to the patients with CCND1 numerical aberration-positive tumors.

3) This suggests that the CCND1 numerical aberrations might be related to the local invasiveness and aggressiveness of OSCCs which could be the cause of poor prognosis.

\section{References}

1. Jemal A, Murray T, Ward E, Samuels A, Tiwari RC, Ghafoor A, Feuer EJ and Thun MJ. Cancer statistics, 2005. CA Cancer J. Clin. 2005;55:10-30.

2. Matta A and Ralhan R. Overview of current and future biologically based targeted therapies in head and neck squamous cell carcinoma. Head Neck Oncol 2009;1(2):6-10.

3. GBD 2015 Risk Factors Collaborators. Global, regional, and national comparative risk assessment of 79 behavioural, environmental and occupational, and metabolic risks or clusters of risks, 19902015: a systematic analysis for the Global Burden of Disease Study 2015. Lancet. 2016 Oct;388(10053):1659-1724.
4. Chaudhuri, Chikhale A, Devrukhkar V, Sapre SB, Sharma BK and Shenoi R. Demographic and clinical profile of oral squamous cell carcinoma patients: A retrospective study. Indian Journal of Cancer 2012;49(1):21-26. 15

5. Gollin S M. Chromosomal alterations in squamous cell carcinomas of the head and neck: window to the biology of disease. Head Neck 2001;23:238-53. 10

6. Reshmi S C, Saunders W S, Kudla D M, Ragin C R nd Gollin S M. Chromosomal Instability and Marker Chromosome evolution in Oral Squamous Cell Carcinoma. GENES, CHROMOSOMES \& CANCER 2004;41:38-46.11

7. Griod S C, Pfeiffer P, Ries J and Pape H D. Proliferative activity and loss of function of tumor suppressor genes as " biomarkers" in diagnosis and prognosis of benign and preneoplastic oral lesions and oral squamous cell carcinoma. Br. J. Oral Maxillofac. Surg. 1998;36:252-60.12

8. Neville B W and Day T A. Oral Cancer and precancerous Lesions. CA Cancer J. Clin. 2002;52(4):195-215. 13

9. Sunil PM, Ramachandan CR, Gokul S and Jaisanghar N. Fluorescence in-situ hybridization technique as a diagnostic and prognostic tool in oral squamous cell carcinoma. J.Oral Maxillofac. Pathol. 2013 Jan-Apr;17(1):61-64. 18

10. Ramadan O R, Sorour F A, Sheikh M S, Azm A F S, Swaify A G and S Riad E S. Molecular Genetic Study of Chromosome 11q13 Aberration in Oral Squamous Cell Carcinoma by Fluorescence in Situ Hybridization. American Journal of Life Science Researches 2014;2(4):534-547.

11. Basnaker M, Srikala S P and Satish B N VS. Cyclin D1 Gene Expression in Oral Mucosa of Tobacco Chewers -An Immunohistochemical Study. Journal of Clinical and Diagnostic Research 2014;8(5):70-75. 23 
12. Morgan DO. Principles of CDK regulation. Nature 1995;374:131-134. 24

13. Hall $\mathrm{M}$ and Peters G. Genetic alterations of cyclins, cyclins dependent kinases and CDK inhibitors in human cancer. Adv. Cancer Res. 1996;68:67-108.27

14. Uzawa N, Sonoda I, Myo K, Takahashi I K, Miyamato R and Amagasa T. Fluorescence in Situ hybridization for detecting genomic alterations of Cyclin D1 and p16 in Oral Squamous Cell Carcinomas. Cancer 2007;110(10):2230-2239. 30

15. Lydiatt W M, Patel S G, O Sullivan B, Brandwein M S, Ridge $\mathrm{J}$ A et al. Head and Neck Cancers-Major Changes in the American Joint Committee on Cancer Eighth Edition Cancer Staging Manual. Cancer 2017; 67(2):122-137.

16. World Health Organization. International Histological Classification of Tumors. 2nd ed. Berlin, Germany: Springer-Verlag, 1998.

17. Merdith S D, Levine P A, Burns J A et al. Chromosome 11q13 amplification in head and neck squamous cell carcinoma: assosiation with poor prognosis. Arch. Otolaryngol Head Neck Surg. 1995;121:7904.

18. Miyamoto R, Uzawa $\mathrm{N}$, Nagaoka $\mathrm{S}$, Nakakuki K, Hirata Y et al. Potential marker of Oral Squamous Cell Carcinoma Aggressiveness detected by fluorescence in situ hybridization in fine-needle aspiration biopsies. Cancer 2002;95:2152-9.

19. Myo K, Uzawa, N, Miyamoto R, Sonoda I, Yuki Y \& Amagasa T. Cyclin D1 gene numerical aberration is a predictive marker for occult cervical lymph node metastasis in TNM stage I and II sqyuamous cell carcinoma of the oral cavity. Cancer 2005;104:2709-16.

20. Rodrigo J P, Garcia-Garracedo D \& Garcia L A. Distinctive clinicopathological association of amplifications of the cortactin gene at
$11 \mathrm{q} 13$ in head and neck squamous cell carcinoma. J. Pathol. 2009;217:516-23.

21. Kaminagakura E, Werneck I, Soares F A, Nishimoto I N, Kowalski L P. CCND1 amplification and protein overexpression in oral squamous cell carcinoma of young patients. Head Neck 2011;33:1413-9.

22. Pathare S M, Gerstung M, Beerenwinkel N, Schäffer A A, Kannan S, Pai P. CLinicopathological and prognostic implications of genetic alterations in oral cancers. Oncology Letters 2011;2(3):445-51.

23. Nimeus E, Baldetorp B, Bendahl P O, Rennstam K, Wennerberg J, Akervall J et al. Amplification of the Cyclin D1 gene is associated with tumor subsite, DNA nondiploidy and high S-phase fraction in squamous cell carcinoma of the head and neck. Oral Oncol. 2004;40(6):624-9.

24. Fujii M, Ishiguro R, Yamashita $T$ \& Tashiro M. Cyclin D1 amplification correlates with early recurrence of squamous cell carcinoma of the tongue. Cancer Letters 2001;172:18792.

25. Huang X, Godfrey $T$ E, Gooding W E, $\begin{array}{llllllll}\text { McCarty } & \mathrm{K} & \mathrm{S} & \mathrm{Jr} & \& & \text { Gollin } & \mathrm{S} & \mathrm{M} \text {. }\end{array}$ Comprehensive genome and transcriptome analysis of the 11q13 amplicon in human oral cancer and synteny to the 7F5 amplicon in murine oral carcinoma. Genes Chromosomes Cancer 2006;45:1058-69.

26. Monteiro L S, Freitas M D, Warnakulasuriya $\mathrm{S}$, Caballero $\mathrm{T}$ G, Vila $\mathrm{J} \mathrm{F}$ and Fraga $\mathrm{M}$. Prognostic Significance of Cyclins A2, B1, D1, and E1 and CCND1Numerical Aberrations in Oral Squamous Cell Carcinomas. Analytical Cellular Pathology 2018:1-10.

27. Mahdey H M, Ramanathan A, Ismail S M, Abraham M T, Jamaluddin M \& Zain R B. Cyclin D1 amplification in tongue and cheek squamous cell carcinoma. Asian Pac J Cancer Prev. 2011;12(9):2199-204. 